\title{
Physical Stability of Oil in Water Emulsions in the Presence of Gamma Irradiated Gum Tragacanth
}

Meybodi, Neda Mollakhalili; Mohammadifar, Mohammad Amin; Farhoodi, Mehdi; Skytte, Jacob Lercke; Abdolmaleki, Khadije

Published in:

Journal of Dispersion Science and Technology

Link to article, DOI:

$10.1080 / 01932691.2016 .1215250$

Publication date:

2017

Document Version

Peer reviewed version

Link back to DTU Orbit

Citation (APA):

Meybodi, N. M., Mohammadifar, M. A., Farhoodi, M., Skytte, J. L., \& Abdolmaleki, K. (2017). Physical Stability of Oil in Water Emulsions in the Presence of Gamma Irradiated Gum Tragacanth. Journal of Dispersion Science and Technology, 38(6), 909-916. https://doi.org/10.1080/01932691.2016.1215250

\section{General rights}

Copyright and moral rights for the publications made accessible in the public portal are retained by the authors and/or other copyright owners and it is a condition of accessing publications that users recognise and abide by the legal requirements associated with these rights.

- Users may download and print one copy of any publication from the public portal for the purpose of private study or research.

- You may not further distribute the material or use it for any profit-making activity or commercial gain

- You may freely distribute the URL identifying the publication in the public portal 


\title{
Physical stability of oil in water emulsions in the presence of gamma irradiated gum tragacanth
}

\author{
Neda Mollakhalili Meybodi ${ }^{1}$, Mohammad Amin Mohammadifar ${ }^{2}$, Mehdi Farhoodi ${ }^{1}$, \\ Jacob Lercke Skytte ${ }^{2}$, Khadije Abdolmaleki ${ }^{1}$ \\ ${ }^{1}$ Department of Food Science and Technology, National Nutrition and Food Technology \\ Research Institute, Faculty of Nutrition Sciences and Food Technology, Shahid Beheshti \\ University of Medical Sciences, Tehran, Iran, ${ }^{2}$ Research Group for Food Production \\ Engineering, National Food Institute, Technical University of Denmark, Lyngby, \\ Denmark \\ Address correspondence to Mohammad Amin Mohammadifar. E-mail: \\ Mohamdif@ut.ac.ir
}

\begin{abstract}
Gum tragacanth (GT) exuded from an Iranian Astragalus species was $\gamma$-irradiated at 0 , $0.75,1.5,3,5,7,10 \mathrm{kGy}$ and used to stabilize a model oil in water emulsion system. Stability and physicochemical properties of emulsion samples were investigated with respect to the effect of irradiation treatment on functional properties of gum tragacanth. Particle size distribution, interfacial tension, zeta potential, steady shear and oscillatory rheological measurements were used to characterize and evaluate the emulsion samples and obtain more information about the possible stability mechanism. Emulsions were prepared by homogenizing $10 \%$ w/w sun flower oil with $90 \%$ w/w aqueous gum dispersions and stored quiescently at $25^{\circ} \mathrm{C}$ for 120 days. Results indicated that using 1.5 kGy irradiated GT was more effective in providing optimum values of apparent viscosity, number mean diameter, electrosteric repulsion and structure strength for getting maximum emulsion stability. GT significantly reduced the interfacial tension of the oil and water system, but no significant differences were observed among all irradiation treated and non-irradiated samples. This study revealed that, GT acts as a bifunctional
\end{abstract}


emulsifier and irradiation treatment has a great positive influence on its ability to reduce droplets collision frequency and stabilize oil in water emulsion.

\section{GRAPHICAL ABSTRACT}

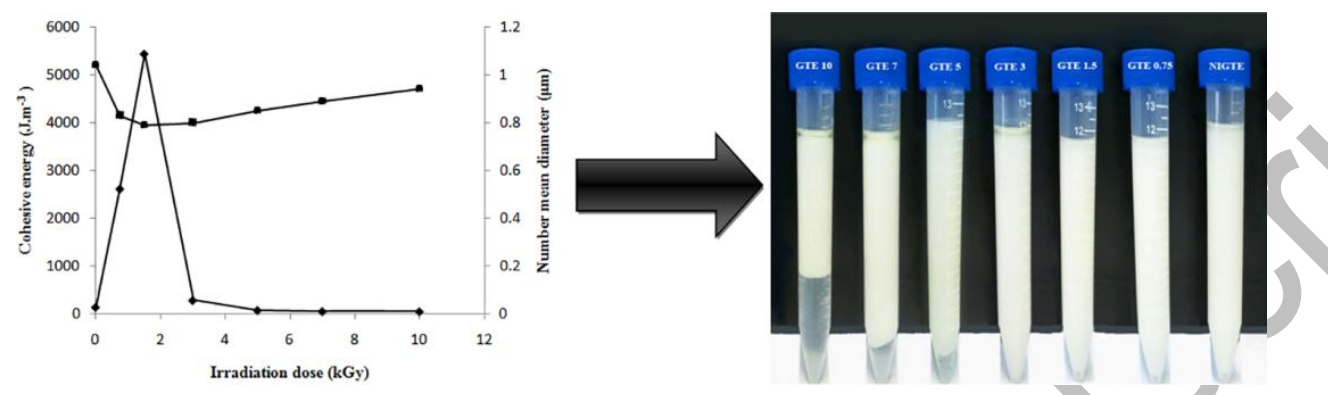

KEYWORDS: Gum tragacanth, Irradiation treatment, Emulsion stability

\section{INTRODUCTION}

Emulsions are thermodynamically unstable systems that are composed of at least two immiscible liquids, such as oil and water. One of which as small spherical droplets, are dispersed in another one. As a result, oil in water (o/w) or water in oil (w/o) emulsion will be formed [1]. Emulsions are the basis of manufactured or natural materials that are used in different industries (i.e. food, pharmaceutical, cosmetic) [2]. Among these, oil in water emulsions have become subjected to a growing attention in the formulation of value added products that contain health ingredients (i.e. vitamins, lipophilic bioactive components, minerals, omega 3) for the functional food markets [3]. One of the major concerns about these systems is keeping them stable during storage and consumption [4]. 
Emulsion instability is due to the increase in interfacial area following emulsification [5]. However, it is possible to form kinetically stable (metastable) emulsions for a reasonable period of time, if their destabilization velocity is sufficiently low compared with the expanded lifespan [6,7]. With this fact in mind, adding substances known as emulsifiers and/or thickening agents prior to homogenization will enhance the emulsion stability against flocculation, coalescence, and creaming, by increasing the activation energy of systems [1]. Emulsifiers contribute in emulsion stability by either reducing the interfacial tension at the freshly formed oil-water interface and/or keeping the newly formed droplets via repulsive colloidal interaction [8]. Thickening agents enhance the emulsion stability by increasing the continuous phase viscosity in order to retard droplet movements and hinder the droplet-droplet contact [5].

Hydrocolloids are one of the components that are used in preparing emulsions and controlling their shelf life either as a thickening agent [9] or emulsifier [10]. However, most hydrocolloids can be considered as thickeners, and only a few are effective as emulsifiers [11].

Gum tragacanth (GT) is a complex, heterogeneous anionic hydrocolloid and has been called a bifunctional emulsifier because it can act either as a thickening and emulsifying agent. Based on Food Chemical Codex, GT is a dried gummy exudation obtained from Astragalus gummifer Labillardiere or other Asiatic species of Astragalus [12]. In accordance with the FDA code of Federal Regulation, it is allowed as a food additive (code number $\mathrm{E}_{413}$ ) at the level of $0.2-1.3 \%$ [13]. It has been used since 1961 in the food, 
pharmaceutical, cosmetic industries due to its perfect resistance to heat and acid [14], high viscosity at low concentration [15], good suspending action and perfect emulsifying and good release properties [16]. It is well known that GT consists of two fractions: water-swellable (bassorin) and water-soluble (tragacanthin) that their ratios are different among different species $[13,17]$. Iran, followed by Turkey and Syria, are the main producers of commercially used GT [13].

It has been reported that GT has unacceptably high microbial contamination levels, previously controlled through fumigation with ethylene oxide (ETO). This process was forbidden around 1987, due to the carcinogenicity of ETO. So it is necessary to apply an alternative treatment to make it safe for food industry consumption [18]. Food irradiation, also called minimal processing technology, is a direct exposure of food products to electron or electromagnetic rays in order to improve their quality and safety. Nowadays, irradiation is used on a commercial scale in more than 55 countries. By increasing the acceptance of commercial use of irradiation, the technology is applied to food ingredients and ready-to-eat meals too. Nowadays, $\gamma$-irradiation as an ionic and non-thermal method, has received more attention to modify the physical properties of natural polysaccharides such as starch [19].

Irradiation has been approved by the IAEA, the FAO, and the WHO, in doses up to 10 $\mathrm{kGy}[20,21]$, although for some specific products it is applicable in doses as high as 75 kGy [22]. 
A few studies have been devoted to investigate the effect of irradiation treatment on the functional properties of natural polysaccharides that are used as rheological modifiers. Some of them revealed that radiation may cause an inverse change in desirable characteristic of gums such as guar, agar, carrageenan, and alginate [21, 23, 24]. But other studies indicated that pectin and salep gums were not influenced by irradiation treatment $[24,25]$.

It is well known that the emulsification and thickening properties of biopolymers are directly related to their solution properties. Also, owing to the fact that solution properties of biopolymers could be affected by irradiation, understanding the influence of different doses of irradiation on efficiency of the GT in stabilizing oil in water emulsions was considered to be the main aim of this study. Stability index measurement, steady shear and oscillatory rheological properties, particle size distribution, interfacial properties, and zeta potential measurements were conducted to get more information on how irradiation treatment affects GT capability in stabilizing the emulsion samples.

\section{MATERIAL AND METHODS}

\subsection{Materials}

Iranian GT (Astragalus Gossypinus) was collected from plants growing in the central mountainous area of Isfahan province, Iran. Taxonomic identification of the gum was performed by an academic member of the Forest, Range, and Watershed Management Organization of Iran. The raw gum was powdered and sieved. Grounded gums with mesh size of between 200 and 500 microns were used in this study. To prepare emulsion, local 
market viable sunflower oil was used. The purity of the oil was controlled and confirmed through standard tests by edible oil laboratory of Iranian National Standards Organization. Sodium azide $\left(\mathrm{NaN}_{3}\right)$ was used to avoid bacterial contamination and obtained from Merck, Darmstadt, Germany.

\subsection{Irradiation}

The powdered gum samples were kept in sealed polyethylene bags and irradiated at 0 , $0.75,1.5,3,5,7,10 \mathrm{kGy}$ at ambient temperature and at a fixed dose rate of $3.41 \mathrm{~Gy} / \mathrm{s}$ from a $\mathrm{Co}^{60} \gamma$-irradiator (Gammacell 220, AECL) at Nuclear Science and Technology Research Centre (Tehran, Iran). The $\gamma$-irradiator was calibrated using the Fricke dosimeter. Cobalt-60, manufactured in Nordion International Co. Ltd., Ottawa, ON, Canada, was used for gamma ray source. The samples were kept at room temperature. Irradiation treated and non-irradiated GT are briefly called IGT and NIGT respectively.

\subsection{Preparation Of Gum Dispersions}

In order to prepare the GT dispersion, $0.5 \mathrm{~g}$ of gum powder $(200-500 \mu \mathrm{m})$ was added to $89.5 \mathrm{~g}$ of distilled water and stirred gently for $2 \mathrm{~h}$ at room temperature. Sodium azide $(0.05 \% \mathrm{w} / \mathrm{w})$ was added to prevent microbial growth. The dispersions were held overnight at $4^{\circ} \mathrm{C}$ to ensure complete hydration before using in emulsion preparation.

\subsection{Production Of $\mathrm{O} / \mathrm{W}$ Emulsions}

For the preparation of O/W emulsions, $10 \%(\mathrm{w} / \mathrm{w})$ sunflower oil was added gradually to the gum dispersions and homogenized for $15 \mathrm{~min}$ at 13,500 rpm by Ultraturax (IKA T25, 
Deutschland, Germany). Emulsions were ice-coated to avoid temperature variation.

Emulsion samples stabilized with irradiation treated GT, areabbreviated GTE (irradiation $_{\text {in }}$ dose), and emulsion samples stabilized by non-irradiated gum tragacanth are abbreviated NIGTE.

\subsection{Emulsion Physical Stability}

Physical stability of emulsions was evaluated by considering the amount of gravitational phase separation. For the measurement of physical stability, freshly prepared emulsions (12 ml) were transferred to cylindrical glass tubes (internal diameter $10 \mathrm{~mm}$, height 120 $\mathrm{mm}$ ), tightly capped and quiescently stored at $25^{\circ} \mathrm{C}$ adjusted incubator. Glass tubes containing emulsions were visually checked for gravitational phase separation throughout 90 days by measuring the height of translucent layer formed at the bottom of emulsions. The emulsion stability index (ESI) was calculated as follows (Eq. (1)):

ESI $\%=\frac{H E-H C+H S}{H E}$

Where HE is the initial emulsion height, $\mathrm{HC}$ is the height of the cream layer and HS is the height of the sedimentation phase. Monitoring tests were performed in triplicate and the mean of the three individual trials was taken for data analysis.

\subsection{Particle Size Analysis}

The particle size distribution of emulsions was measured immediately after preparation of samples and at $5^{\text {th }}, 15^{\text {th }}, 30^{\text {th }}, 60^{\text {th }}, 90^{\text {th }}$, and $120^{\text {th }}$ days subsequently at room temperature $\left(25^{\circ} \mathrm{C}\right)$. Particle size distribution parameters of emulsions were determined by laser diffraction system (Cilas 1090 particle size analyzer, Orleans, France) equipped with a 
He-Ne laser beam at a wavelength of $633 \mathrm{~nm}$. The samples were added to the measuring unit containing distilled water to be diluted 1:100 in order to avoid multiple scattering effects. The measurement was started when droplets were fully dispersed and reached an obscuration of at least $6 \%$. Samples were continually stirred during the measurements to make sure that the emulsions were homogenous. Particle size characteristics were reported as $\mathrm{D}_{0.1}, \mathrm{D}_{0.5}$ and $\mathrm{D}_{0.9}$ on a volume base that indicate the size of particle which $10 \%, 50 \%$, and $90 \%$, of the sample particles are respectively smaller. Fraunhofer theory was used to calculate other parameters automatically. The volume mean average diameter (De Broucker diameter) and average mean diameter were calculated respectively as follows:
$\mathrm{d} 4,3=\sum n_{i} d_{i}^{4} / \sum n_{i} d_{i}^{3}$
d $1,0=\sum n_{i} d_{i}^{1} / \sum n_{i}$

Where $n_{i}$ is the number of particles of class " $\mathrm{i}$ " and $d_{i}$ is the diameter of class " $\mathrm{i}$ ". Span as an indicator of the polydispersity of the size distribution on volume basis was calculated using the following equation:

$$
\operatorname{Span}=\frac{d_{0.9}-d_{0.1}}{d_{0.5}}
$$

It should be noted that, all measurements were done for physically stable samples.

\subsection{Interfacial Tension Measurement}

Interfacial tension was measured according to Du Nouy ring pull method by a Krüss digital tensiometer K100 (Krüss Instruments, Germany) equipped by standard ring probe and SV 20 Glass vessel. In order to remove surface active contaminants effectively, all 
glassware in contact with the sample were previously cleaned in a acetone bath and rinsed with plenty of double-distilled water, heated in a Bunsen burner flame, and left to cool to room temperature. Samples were kept at room temperature and were stirred for 1 min prior to measurement.

\subsection{Zeta Potential}

In order to measure the zeta potential of emulsions in the presence of irradiation treated GT at different doses they were diluted (1:2000) and loaded in cuvettes and their zeta potentials determined using a Brookhaven Zeta Sizer 90 plus.

\subsection{Rheological Properties}

Rheological properties of emulsions, including steady state and oscillatory, were obtained using Physica MCR 301 rheometer (Anton Paar GmbH, Graz, Austria) equipped with a concentric cylinder measurement system with a radius ratio of 1.0846 . The temperature was controlled using a Peltier system outfitted by fluid circulator. Rheological data were collected using Rheoplus software version 3.21 (Anton-Paar).

Flow curves were obtained at shear rates of $0.01-1000 \mathrm{~s}^{-1}$ and at $1-1000 \mathrm{~s}^{-1}$, when the behavior of the system approached Newtonian). A power law model was used to describe the rheological properties of emulsions. The flow behavior index (n) and consistency coefficient $(\mathrm{m})$ values were obtained by fitting the shear rate versus apparent viscosity to the power law model, Eq. (5):

$\mu_{\mathrm{a}}=m \cdot \dot{\gamma}^{n-1}$ 
Where $\mu_{\mathrm{a}}$ is the apparent viscosity $(\mathrm{Pa} . \mathrm{s}), \mathrm{m}$ is the consistency coefficient $\left(\mathrm{Pa}^{\mathrm{n}} \mathrm{s}^{\mathrm{n}}\right), \gamma$ is the shear rate $\left(\mathrm{s}^{-1}\right)$ and $\mathrm{n}$ is the flow behavior index (dimensionless).

Strain sweep tests were done $(0.1-600 \% ; 1 \mathrm{~Hz})$ to determine the following parameters: (1) the linear region of viscoelasticity or $\gamma_{\mathrm{LVE}}$ (limiting value of reversible strain induced structural change); (2) the elastic modulus at linear viscoelastic range $\left(\mathrm{G}^{\prime} \mathrm{LVE}\right)$ as measure of structural strength; (3) the damping factor $(\tan \delta)$ to provide a direct view of whether the samples behaved as liquid or solid and (4) cohesive energy $\left(E_{C}\right)$ which could be used in a quantitative manner as a measure of the extent and strength of interaction between rheological units in an emulsion system.

$$
\mathrm{EC}=1 / 2 G_{L V E}^{\prime} \times \gamma_{L V E}^{2}
$$

Frequency sweep tests were carried out at frequency of $0.05-50 \mathrm{~Hz}$ and constant strain of $1 \%$ to evaluate the dynamic rheological properties such as $\mathrm{G}^{\prime}$ and $\mathrm{G}^{\prime \prime}$ and damping factor $(\tan \delta)$ as a function of strain rate.

\subsection{Statistic Analysis}

Analytical values are based on the mean and standard deviation of three replicates. For all rheological measurements, the reported values are based on the mean of three replicates. Analysis of variance (one-way ANOVA) was used for the data analysis (SPSS 16.0). Duncan's multiple-range test was used to compare treatment means.

\section{RESULTS AND DISCUSSION}

\subsection{Emulsion Stability}


The emulsion stability index decreased for all the samples over the storage period at $25^{\circ} \mathrm{C}$. As shown in Figure 1, emulsion stability was improved along with increasing the irradiation dose up to $1.5 \mathrm{kGy}$. Results indicated that the $\mathrm{GTE}_{1.5}$ (emulsions containing $1.5 \mathrm{kGy}$ irradiated GT) had the least creaming index during 120 days storage (Fig. 1). Creaming index is an indirect index used to provide information about the extent of droplet aggregation in emulsions. So the higher stability of GTE 1.5 may be attributed: 1) higher viscosity of the external phase to reduce droplets collision [10]; 2) lower interfacial tension because of the better adsorption of IGT at oil-water interface [26]; 3) higher polymeric steric hindrance. Unfortunately, there are just a few published papers and reports about the effects of irradiation treatment on the structure, functional properties and the possible applications of rheology modifiers and food stabilizers. Considering previous published data, it seems that irradiation dose has a great influence on the structure, particle size distribution, intermolecular interactions, solubility and rheological properties of gum dispersions [22]. These are important factors which may affect the three mentioned mechanisms of stability to various extent. It is possible that a combined effect of better intermolecular interactions and more mobility of gum strands due to $1.5 \mathrm{kGy}$ irradiation treatment are responsible for better stability of oil in water emulsion samples. In order to get a primary view about the effects of irradiation dose on emulsion stabilizing performance of GT, particle size distribution of emulsion samples were measured and evaluated.

\subsection{Particle Size Distribution}


Droplet size distribution is of great importance because of its fundamental information about many characteristics such as the rheology [27], the stability of emulsion and performance of stabilizers [28]. According to the stocks law, the velocity of phase separation in an emulsion is proportional to the square of its dispersed phase radius. GT can rearrange at oil-water interface in a manner to postpone unfavorable interaction and reduce particle size to a considerable amount [29]. Diameter statistics including $\mathrm{d}_{0.1}, \mathrm{~d}_{0.5}$, $\mathrm{d}_{0.9}, \mathrm{~d}(4,3), \mathrm{d}(1,0)$ and span values for oil in water emulsions containing $0.5 \% \mathrm{w} / \mathrm{w}$ IGT and NIGT are presented in table 1 . It should be noted that $\mathrm{d}_{0.1}, \mathrm{~d}_{0.5}, \mathrm{~d}_{0.9}, \mathrm{~d}(4,3)$ are volume based parameters and $\mathrm{d}(1,0)$ is more sensitive to the number of particles in distribution. Span values were calculated by means of equation (4), to evaluate the effect of irradiation treatment on polydispersity of large polysaccharide particles and emulsion droplets or aggregates. Results showed that irradiation treatment application modified particle size distribution. As shown in table 1, there are substantial differences between $\mathrm{d}(4,3)$ and $\mathrm{d}(1,0)$ values for all samples. This can be allied to the presence of a range of particle sizes in distribution. Possible particles in samples are individual oil droplets, oil droplet aggregates, water soluble (tragacanthin) and water swellable (bassorin) fractions of gum tragacanth. In addition to the direct effects of the two mentioned gum fractions on particles polydispersity, they probably have a great influence on the particle size distribution by reducing oil droplet aggregation process. It should be noted that in comparison to tragacanthin, bassorin fraction of GT consists of much larger polysaccharide particles which is more prone to irradiation treatment. Table 1 shows that $0.75 \mathrm{kGy}$ irradiation treatment decreased the volume mean diameter to the half of its initial value. This result together with lower value of span which shows higher uniformity 
of particles for the mentioned irradiated samples confirmed that larger particles are more susceptible to degradation when they are exposed to irradiation treatment. Results indicated that while the volume mean diameter and also polydispersity of particles were deceased by irradiation up to $1.5 \mathrm{kGy}$ and from 5 to $10 \mathrm{kGy}$, irradiation between 3 and 5 kGy led to a significant increase in $\mathrm{d}(4,3)$ and span. It was reported that in polydisperse systems like current samples, the number mean diameter is mainly influenced by small oil droplets and apparently the water swellable fraction of gum tragacanth governs the $d$ $(4,3)$ values [30]. Previous study on GT dispersions has pointed out that irradiation treatment of $3 \mathrm{kGy}$ reduced the side branches of GT to the extent that, they are able to develop intermolecular associations or new entanglements between the poorly sidebranched main chains in aqueous media [22]. So considering the constant values of number mean diameter at medium irradiation doses, the increase in volume mean diameter of $\mathrm{GTE}_{3}$ can be more related to the association of large polysaccharide fractions of GT rather than oil droplet unification. Emulsion stability index data corroborates this assumption. Irradiation treatment of biopolymers at high doses resulted in molecular weight reduction and similar results were reported by [31,32]. Results presented in Table 1 indicated that irradiation treatment decreased the systems polydispersity from 3.5 to 1.27 . The decrease in volume mean diameter and increase in number mean diameter that is obseryed in $\mathrm{GTE}_{5}$, and systems containing higher doses irradiated GT, could be related to the resulted lower molecular weight polysaccharides and their less ability to prevent aggregation process of oil droplets. With regard to bifunctional application of GT, either as thickening agent and emulsifier, particle size distribution data alone is not enough to describe the ability of the IGT as stabilizer in oil in water emulsions. 
Therefore, in order to get more information about the mechanisms of stabilization with IGT, more explications particularly in terms of interfacial tension, zeta potential and steady and unsteady state rheological properties of the samples are required.

\subsection{Interfacial Tension Measurements}

Emulsifiers are amphiphiles that lower the interfacial tension between two immiscible phases and thereby reduce the amount of work that must be done to overcome the interfacial tension between the two phases. They also take part in the stabilization of dispersed phase either via electrostatic or steric effects [33].In order to determine the effect of irradiation treatment on emulsifying activity of gum tragacanth, the ability of $0.5 \% \mathrm{w} / \mathrm{w}$ IGT and NIGT to reduce the interfacial tension of the emulsion samples were measured and presented in Figure 2. Results indicated that all IGT and NIGT were able to reduce the interfacial tension from $21 \mathrm{mN} / \mathrm{m}$ to about $8 \mathrm{mN} / \mathrm{m}$, and irradiation treatment had no significant effect on this function.

Previous studies demonstrated that gums surface activity is due to the presence of galactose units and protein residue in their structure [34]. Considering the fact that certain dose of irradiation increased the stability of emulsion samples but had no effect on interfacial tension, it could be concluded that the mentioned correlation between structure and interfacial tension is not affected by irradiation. As the higher stability of $\mathrm{GTE}_{1.5}$ was not due to the better interfacial activity of IGT than other samples and considering the large size of GT's polysaccharides and its anionic nature it seems that measuring zeta 
potential, steady and unsteady state rheological properties is necessary to get more information about the mechanism of stabilization of the samples.

\subsection{Zeta Potential}

Zeta potential $(\zeta)$ has been widely measured and reported to give more insight on emulsifier effectiveness and also to predict long-term stability of colloidal systems [10]. The zeta-potential is the electrical potential at the "shear plane" which is defined as the distance away from the droplet surface below which the oppose-ions remain strongly attached to the droplet when it moves in an electrical field [35]. In other words, the droplet surface charge is considered by measuring zeta potent. Hydrocolloids that are able to create electrostatic repulsion between dispersed oil droplets in oil in water emulsion are liable to make stable emulsions [1] It should be noted that adsorption of layers which increase emulsion stability sterically will lead to a lower zeta potential, which is however not an indication of a reduced electrostatic repulsion [36]. Stabilizer adsorption shifts the plain of shear (where the zeta potential is measured); to a larger distance from the particle surface and lowered the measured zeta potential. In cases of combined electrostatic and steric stabilizers, a zeta potential of about $20 \mathrm{mV}$ is enough to fully stabilize the system [37].

Zeta potential amounts of emulsions containing IGT are presented in Figure 3. The overall charge of the emulsions droplets was negative since GT has a negative charge in mildly acidic solutions due to the presence of ionized carboxylic groups along its backbone that have $\mathrm{pK}_{\mathrm{a}}$ values around 3. As demonstrated, the least (-30.03) and most 
negative (-43.42) values of zeta potential were found for $\mathrm{GTE}_{10}$ and $\mathrm{GTE}_{0.75}$ respectively. It is assumed that irradiation treatment at $0.75 \mathrm{kGy}$, removes the gum entanglements in a way that increases the electrostatic repulsion between oil droplets and thereby an improved network of forces. Higher irradiation doses resulted in degradation of polysaccharide and a decrease in zeta potential. The mentioned decline could be related to the amount of surface area above or? the need for full surface coverage. It is wellknown that increasing the stabilizer concentrations (above the plateau of the adsorption isotherm) decreases the diffuse layer leading to a decreased zeta potential and physical stability [38]. Previous studies reported that lower molecular weight polysaccharide had less ability to stabilize samples through both steric mechanism and rheology modifying function [39]. Results indicated that the zeta potential value and thickness of adsorbing layer could be considered important factors that have a great influence on the stability index of samples. With respect to the previous reports about the adverse effect of irradiation on the size and rheology of GT dispersions, it seems that the role of IGT on stability of samples should also be studied by measuring rheological properties.

\subsection{Rheology Of Emulsions}

\subsubsection{Steady Shear Rates}

Flow curves of $10 \% \mathrm{w} / \mathrm{w}$ oil in water emulsions containing $0.5 \% \mathrm{w} / \mathrm{w}$ IGT at different doses are presented in Figure 4. Here, it can be seen that samples showed different pattern of shear thinning behavior. The different patterns of apparent viscosity vs. shear rate at low shear rates could be attributed to the differences in molecular weight, polydispersity of particles, and characteristic of internal structural forces. Higher 
viscosity, upward trend, and the high shear sensitivity of NIGTE sample at low shear rates could be related to the presence of lager particles of water swellable part of GT among other majority of small ingredients like oil droplets and soluble part of GT. Lower slope of apparent viscosity at low shear rates was observed for samples containing IGT up to $1.5 \mathrm{kGy}$. This could be related to degradation of large particles and increasing uniformity by irradiation treatment up to the mentioned dose of irradiation. Shear rate dependency of viscosity at the low shear rate range increased by increasing irradiation dose from 1.5 to $5 \mathrm{kGy}$ and decreased for irradiation doses in the range of 5 to $10 \mathrm{kGy}$. The mentioned assumptions about changing in polydispersity are confirmed by the span values reported in Table 1. It should be noted that the span values have been reported for volume base size distribution data which practically are more sensitive to the presence of larger particles in sample. Power-law model parameters were fitted to middle range shear rate data and consistency coefficient and flow behavior index were reported for all samples in Table 2. Results indicated that using $0.75 \mathrm{kGy}$ IGT for stabilizing emulsion increased consistency coefficient about 1.6 times. Following the initial increase, a huge decrease of about 42 times in consistency value was observed by increasing the irradiation dose up to $10 \mathrm{kGy}$. As shown in Table 2, in contrast to consistency coefficient, flow behavior index values of samples increased from 0.38 to 0.76 , which means irradiation has a great effect on reducing shear dependency behavior of emulsion samples. Similar trends were observed for simple systems of IGT dispersion, but maximum value of consistency coefficient was reported for 3kGy GT samples [22]. This similarity between GT contained emulsion and GT dispersions reveal that rheology of the emulsion samples are mainly governed by the effect of GT in continuous phase. With 
respect to the stability value and the flow curve pattern of $\mathrm{GTE}_{1.5}$ samples, it is evident that the lowering of polydispersity with the expense of a few reductions in the size of initial large polysaccharide particles can change the inter-particle forces in a way that enhance stability. To get more information about the effect of GT samples on structure strength and type of structure, evaluation of network of forces in the emulsion samples have been done by performing frequency sweep tests.

\subsubsection{Oscillatory Testing}

\subsubsection{Strain Sweep}

Strain sweep tests of oil in water emulsions containing $0.5 \% \mathrm{w} / \mathrm{w}$ IGT at different doses have been done, and the related rheological parameters are reported in Table 3 . The lengths of the LVE indicated that $\mathrm{G}^{\prime}$ and $\mathrm{G}^{\prime \prime}$ values are independent of the oscillation strain (reversible elasticity). The results indicated that the maximum values of $\mathrm{G}^{\prime}{ }_{\text {LVE }}$ (as a measure of structural strength) belongs to NIGTE but for GTE 1.5 samples, $\gamma_{L V E}$ or $\gamma_{L}$ (limiting value of reversible strain induced structural change) and cohesive energy $\left(\mathrm{E}_{\mathrm{C}}\right)$ value (a measure of the extent and strength of inter droplet interactions, were significantly higher than other samples. Results indicated that decomposition of GT, up to a certain value, enhanced the stability of the viscoelastic emulsion sample under $\gamma$ amplitude. These results are in agreement with previous studies reporting that the increase in $\gamma_{L}$ is related to higher amount of low molecular weight fraction of GT [13]. Correlation between the emulsion stability and reported rheological parameters (obtained at frequency of $1 \mathrm{~Hz}$ ), indicated that higher $\tan \delta$ and $\mathrm{E}_{\mathrm{C}}$ values would lead to producing more stable emulsions. However, both of the mentioned parameters are frequency 
dependent and give limited information about structure and network of forces. So in order to get more information about the interaction among colloidal particles and droplets, viscoelastic properties of samples should be determined as a function of timescale.

\subsubsection{Frequency Sweep}

All the frequency sweep tests for $10 \% \mathrm{w} / \mathrm{w}$ oil in water emulsions containing $0.5 \% \mathrm{w} / \mathrm{w}$ different doses IGT were performed in the linear viscoelastic region. In order to reduce the possibility of the microstructures damaging and based on the amplitude sweep profile, $\gamma=1 \%$ was chosen and the results presented in Figure 5. In analyzing frequency sweep data, absolute values of storage and loss moduli and also their frequency dependency must be considered. The $\mathrm{G}^{\prime}$ and $\mathrm{G}^{\prime \prime}$ values and also pattern of frequency sweep data for the emulsion samples are mainly depended on the size and molecular weight of ingredient, entanglement of biopolymers, extent and strength of physical or chemical bonds, polydispersity of particles and some other solution properties of the system. Results indicated that increasing the irradiation dose decreased both $\mathrm{G}^{\prime}$ and $\mathrm{G}^{\prime \prime}$ of emulsion samples over the whole frequency range. It should be noted that up to $3 \mathrm{kGy}$, elastic modulus experienced more reduction compared to loss modulus and this was more pronounced in lower frequency range. While frequency sweep curves for the NIGTE was comparable to the one expressed by viscoelastic gel-like systems, a pattern similar to the mechanical spectra of entanglement networks showing wide molecular mass distribution was observed for the rest of the samples (except for $\mathrm{IGTE}_{10}$ ) [40]. By increasing the irradiation dose from 3 to $5 \mathrm{kGy}, \mathrm{G}^{\prime}$ became less sensitive and $\mathrm{G}^{\prime \prime}$ decreased faster, so crossover frequency started to decrease from 1.58 to $0.8 \mathrm{~Hz}$. For irradiation doses higher 
than $5 \mathrm{kGy}$ both moduli were slightly increased and as $\mathrm{G}^{\prime}$ increased faster, crossover frequency continued to decrease. Thus, a similar pattern to NIGTE sample, but with lower values of $\mathrm{G}^{\prime}$ and $\mathrm{G}^{\prime \prime}$, was created again for $\mathrm{IGTE}_{10}$. With respect to the irradiation treatment effect on particle size values and frequency sweep patterns, it seems that irradiation treatment up to $3 \mathrm{kGy}$ degrades the large particles or aggregates of bassorin fraction. So, by reducing hydrophobic interactions, the gel like structure has been changed to a less organized structure (higher values of tan $\delta$ reported in Table 3 , confirmed development of more liquid like structure). Irradiation treatment up to $5 \mathrm{kGy}$ led to more reduction in polysaccharides size, weaker viscose forces, and less energy loss. The faster decrease of $G^{\prime \prime}$ resulted in lower value of $\tan \delta$. At higher irradiation doses up to $10 \mathrm{kGy}$, viscosity effect of highly degraded polysaccharide in continuous phase was not enough to prevent interactions between oil droplets interface and retarding coalescence, so elastic modulus was increased and $\tan \gamma$ reached its least value in Table 3 .

\section{CONCLUSION}

A multi-practical attitude revealed that irradiation treatment of GT had a significant effect on its performance in stabilizing oil in water emulsion. The results suggested that the gum retarded emulsion instability by reducing the interfacial tension, increasing the viscosity of the continuous phase, increasing electrostatic repulsion, lowering the mean droplet size and polydispersity. It seems that increasing the irradiation dose up to 1.5 $\mathrm{kGy}$, breaks the side branches or backbone of GT to such extent that is needed to act as an efficient energy barrier to prevent the droplets from coming close enough together to aggregate. Highest values of damping factor at linear viscoelastic range, cohesive energy, 
and least values for $\mathrm{D}_{0.1}$ and number-average particle size were found for the most stable sample which was produced using IGT $1.5 \mathrm{kGy}$.

\section{ACKNOWLEDGMENT}

We are grateful to the Department of Food Science and Technology, National Nutrition and Food Technology Research Institute, Shahid Beheshti University of Medical Sciences for support of this study.

\section{REFERENCES}

[1] McClements, D.J. (2005) Food Emulsions: Principles, Practice and Technique; Washington: CRC Press.

[2] Achouri, A., Zamani, Y and Boye, J. I. (2012) Journal of Food Research,1: 254-267.

[3] McClements, D. J., Decker, E. A and Weiss, J. (2007) Journal of Food Science, 72: $109-124$.

[4] Gavlighi, H. A., Meyer, A. S., Zaidel , D. N. A., Mohammadifar M. A. and Mikkelsen, J.D. (2013) Food Hydrocolloids, 31: 5-14.

[5] Mollakhalili Meybodi, Neda., Mohammadifar, M.A. and Naseri, A.R. (2014) Journal of Food Quality and Hazard Control, 1: 67-71.

[6] Silva, K. A., Rocha-Leão, M. H. M. and Coelho A. Z. (2010) Journal of Food

Engineering, 97: 335-340.

[7] Trujillo-Cayado, L.A., Alfaro, M.C. Muñoz, J., Raymundo, A and Sousa, I. (2016) Colloid Surface B, 141: .53-58. 
[8] Ghosh, S. and Rousseau, D. (2011) Current Opininion in Colloid \& Interface, 16: 421-431.

[9] Saha, D and Bhattacharya, S. (2010) Journal of Food Science and Technology,47: 587-597.

[10] E.Dickinson. (2009) Food Hydrocolloids, 23: 1473-1482.

[11] E.Dickinson. (2001) Colloids and Surfaces. B, 20: 197-210.

[12] Anderson, D. M. W. and E.Bridgeman, M. M.(1985) Phytochemistry, 24: 23012304.

[13] Balaghi, S., Mohammadifar, M. A., Zargaraan, A., Gavlighi, H. A. and Mohammadi, M. Food Hydrocolloids, 25: 1775-1784.

[14] Gorji, E. G., Mohammadifar, M. A. and Ezzatpanah, H. (2011) International Journal of Dairy. Technology, 64: 262-268.

[15] Pangborn, R. M., Trabue, I. M. and Szczesniak, A. S. (1973) Journal of Texture Studie, 4: 224-241.

[16] Org, C., Weiping, W., Phillips, G. and Williams, P. A. Handbook of hydrocolloid, second ed., Woodhead Publishing, 2000.

[17] Mollakhalili Meybodi, N., Mohammadifar, M.A. (2014) Journal of food quality and hazards control, 1(2): 46-51.

[18] Golmohammadi, F. (2013) Technical Journal of Engineering and Applied Sciences, 3: 3702-3721.

[19] Farkas, J. and Mohácsi-Farkas, C. (2011) Trends Food Science and Technology, 22: 121-126. 
[20] Farag Zaied, S., Mohamed Youssef, B., Desouky, O. and Salah El Dien, M. (2007) Applied Radiation and Isotopes, 65: 26-31.

[21] Aliste, A. J., Vieira, F. F. and Del Mastro, N. L. (2000) Radiation Physics and Chemistry, 57: 305-308.

[22] Alijani, S., Balaghi, S. and Mohammadifar, M. A. International Journal of Biological Macromolecule,49: 471-479.

[23] Gupta, S., . Shah, B., Sanyal, B., Variyar, P. S. and Sharma, A. (2009) Food Hydrocolloids, 23: 1785-1791.

[24] Dogan, M., Kayacier, A. and Ic, E. (2007) Food Hydrocolloids, 21: 392-396.

[25] F.Krahl., K. F.Arndt,Synthesis of microgels by radiation methods, Springer Berlin Heidelberg, City, 2011.

[26] Liu, H., Wang, B., Barrow, C. and Adhikari J. B. (2014) Food Chemistry 143: 484491.

[27] Asano,Y. and .Sotoyama, K. (1999) Food Chemistry 66: 327-331.

[28] Gallegos, C., Partal, P. and Franco, J.M. (2009) American Journal of Health-System Pharmacy 66: 162-166.

[29] Farzi, M., Emam-Djomeh, Z. and Mohammadifar M. A. (2013) International Journal of Biological Macromolecule 57: 76-82.

[30] Karimi, N. and Mohammadifar, M. A.(2014) Food Hydrocolloids 37: 124-133.

[31] Atayama, T., .Nakauma, M., Todoriki, S., Phillips, G. O. and Tada, M. (2006) Food Hydrocolloids 20: 983-989.

[32] Blake, S. M., Deeble, D. J., Phillips, G. O. and Du Plessey, A. (1988) Food Hydrocolloids 2: 407-415. 
[33] Singh, H. and Sarkar Adva, A. (2011) Colloid and Interface 165: 47-57.

[34] Moreira, R., Chenlo, F., Silva, C., Torres, M. D., Díaz-Varela, D., Hilliou, L. and Argence, H. (2012) Food Hydrocolloids 28: 284-290.

[35] Rezvani, E., Schleining, G. and Taherian, A. R. A LWT - Food Science and Technology International 48: 82-88.

[36] Ait-Akbour, R., Boustingorry, P., . Leroux, F., . Leising, F. and Taviot-Guého, C. (2015) Journal of Colloid and Interface Science437: 227-234.

[37] Arunkumar, N., Deecaraman, M. and Rani, C. Nanosuspension technology and its applications in drug delivery, 2009.

[38] Zaman, A. (2000) Colloid and Polymer Science 278: 1187-1197.

[39] Dickinson, E. (2010) Current Opinion in Colloid and Interface Science 15: 40-49.

[40] Chamberlain, E. K., .Rao, M. A. (2000) Food hydrocolloids 14: 163-171. 
Table 1. Particle size analysis of emulsions containing $0.5 \% \mathrm{w} / \mathrm{w}$ of different doses $\gamma$ irradiated gum tragacanth

\begin{tabular}{|l|l|l|l|l|l|l|}
\hline Irradiation \\
dose $(\mathrm{kGy})$
\end{tabular}

Values with different letters $(\mathrm{a}-\mathrm{f})$ in each column are significantly different $(p<0.05)$. 
Table 2. Parameters of power-law model for the emulsion samples containing native and different doses irradiated gum tragacanth $(0.5 \% \mathrm{w} / \mathrm{w})$.

\begin{tabular}{|c|c|c|c|c|}
\hline \multirow{2}{*}{$\begin{array}{l}\text { Irradiation dose } \\
(\mathrm{kGy})\end{array}$} & \multicolumn{4}{|c|}{ Power law parameters } \\
\hline & $\mathrm{a}\left(\right.$ pa. $\left.\mathrm{s}^{\mathrm{n}}\right)$ & $\mathrm{b}\left(\gamma^{\prime}=0.05 \mathrm{~s}^{-1}\right)$ & $r$ & $\mu\left(\gamma=0.05 \mathrm{~s}^{-1}\right)$ \\
\hline 0 & $1.88^{\mathrm{b}}$ & $0.42^{\mathrm{e}}$ & 0.99 & 11.8 \\
\hline 0.75 & $2.93^{\mathrm{a}}$ & $0.38^{f}$ & 0.99 & $6.16^{b}$ \\
\hline 1.5 & $1.96^{b}$ & $0.42^{\mathrm{e}}$ & 0.99 & $3.80^{\mathrm{c}}$ \\
\hline 3 & $0.81^{\mathrm{c}}$ & $0.54^{\mathrm{e}}$ & 0.98 & $5.56^{b}$ \\
\hline 5 & $0.22^{\mathrm{d}}$ & $0.68^{\mathrm{c}}$ & 0.99 & $5.50^{b}$ \\
\hline 7 & $0.17^{\mathrm{d}}$ & $0.72^{b}$ & 0.99 & $5.48^{b}$ \\
\hline 10 & $0.08^{\mathrm{e}}$ & $0.76^{\mathrm{a}}$ & 0.99 & $1.46^{\mathrm{d}}$ \\
\hline
\end{tabular}

Values with different letters $(\mathrm{a}-\mathrm{f})$ in each column are significantly different $(p<0.05)$. 
Table 3. Cohesive Energy (Ec), structural strength $\left(\mathrm{G}_{\mathrm{LVE}}^{\prime}\right)$, limiting value of strain $\left(\gamma_{\mathrm{L}}\right)$, and loss-tangent value $\left(\tan \delta_{\mathrm{LVE}}\right.$ (in the linear viscoelastic range of emulsion containing IGT and NIGT, as determined by strain sweep tests at $25^{\circ} \mathrm{C}$ and a frequency of $1 \mathrm{~Hz}$.

\begin{tabular}{|l|l|l|l|l|}
\hline $\begin{array}{l}\text { Irradiation } \\
(\mathrm{kGy})\end{array}$ & $\mathrm{Ec}\left(\mathrm{J}^{-\mathrm{m}^{-3}}\right)$ & $\mathrm{G}_{\mathrm{LVE}}^{\prime}(\mathrm{Pa})$ & $\gamma_{L}(\%)$ & $\tan \boldsymbol{\delta}_{L V E}$ \\
\hline 0 & & & & \\
\hline 0.75 & $2613^{\mathrm{e}}$ & $4.80^{\mathrm{e}}$ & $33.05^{\mathrm{d}}$ & $0.94^{\mathrm{bc}}$ \\
\hline 1.5 & $5433^{\mathrm{f}}$ & $3.08^{\mathrm{d}}$ & $59.40^{\mathrm{e}}$ & $1.12^{\mathrm{c}}$ \\
\hline 3 & $281^{\mathrm{d}}$ & $1.67^{\mathrm{c}}$ & $18.35^{\mathrm{c}}$ & $1.29^{\mathrm{d}}$ \\
\hline 5 & $73^{\mathrm{b}}$ & $1.35^{\mathrm{b}}$ & $10.40^{\mathrm{b}}$ & $1.19^{\mathrm{e}}$ \\
\hline 7 & $50^{\mathrm{a}}$ & $0.92^{\mathrm{a}}$ & $10.41^{\mathrm{b}}$ & $0.99^{\mathrm{b}}$ \\
\hline 10 & $47^{\mathrm{a}}$ & $0.87^{\mathrm{a}}$ & $10.40^{\mathrm{b}}$ & $0.58^{\mathrm{a}}$ \\
\hline
\end{tabular}

Values with different letters $(\mathrm{a}-\mathrm{f})$ in each column are significantly different $(p<0.05)$. 
Figure 1.

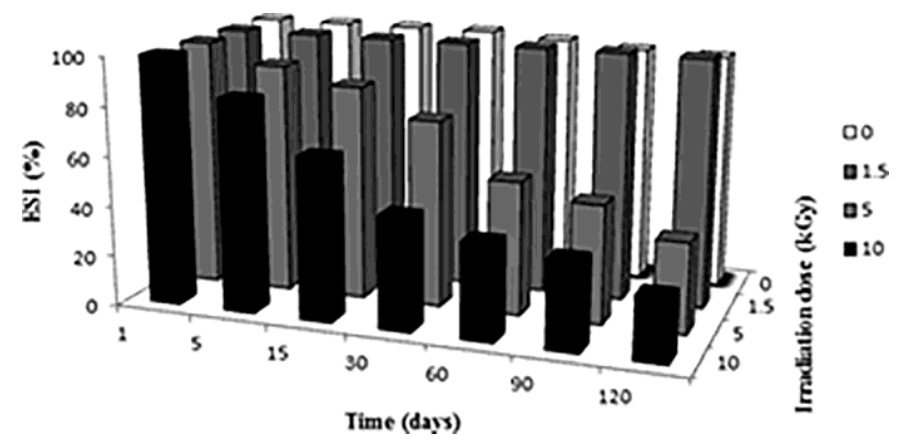


Figure 2.

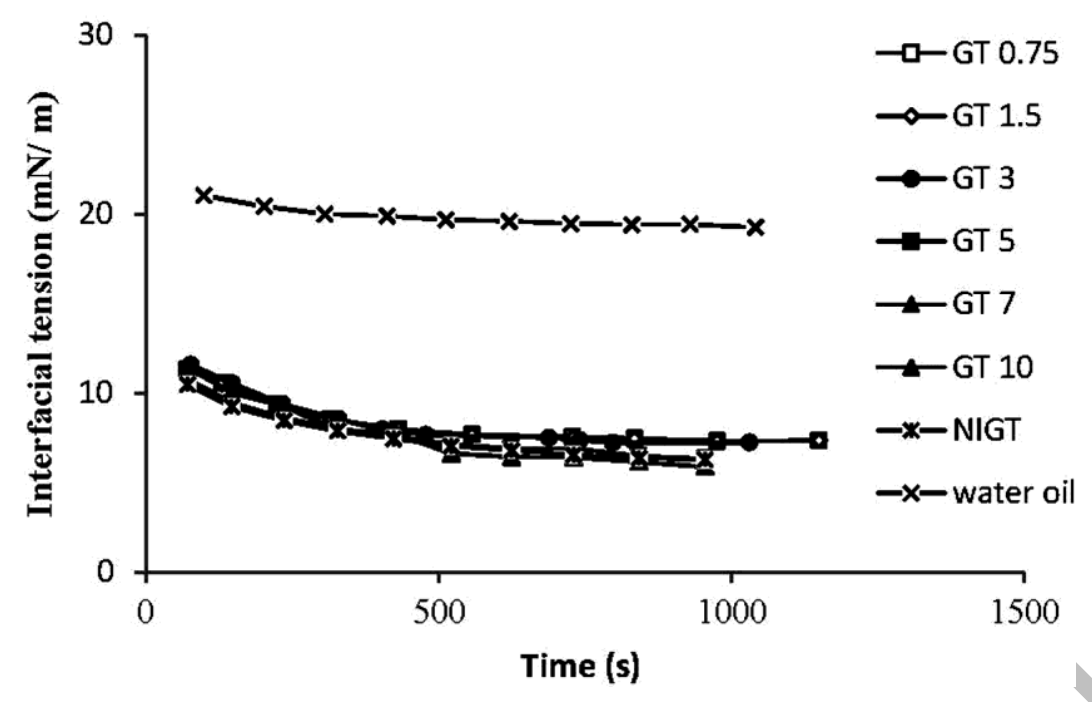


Figure 3.

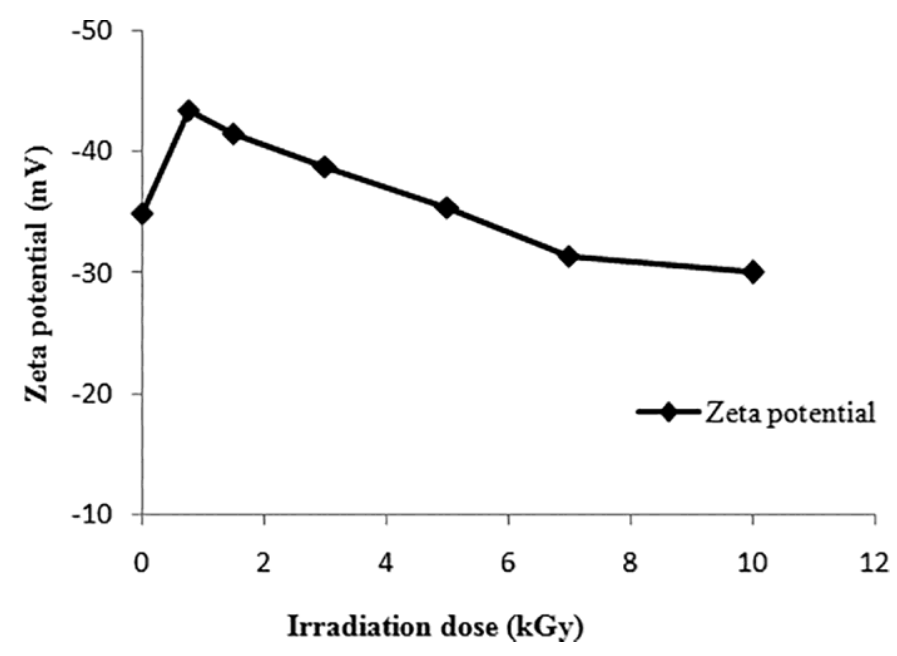


Figure 4.

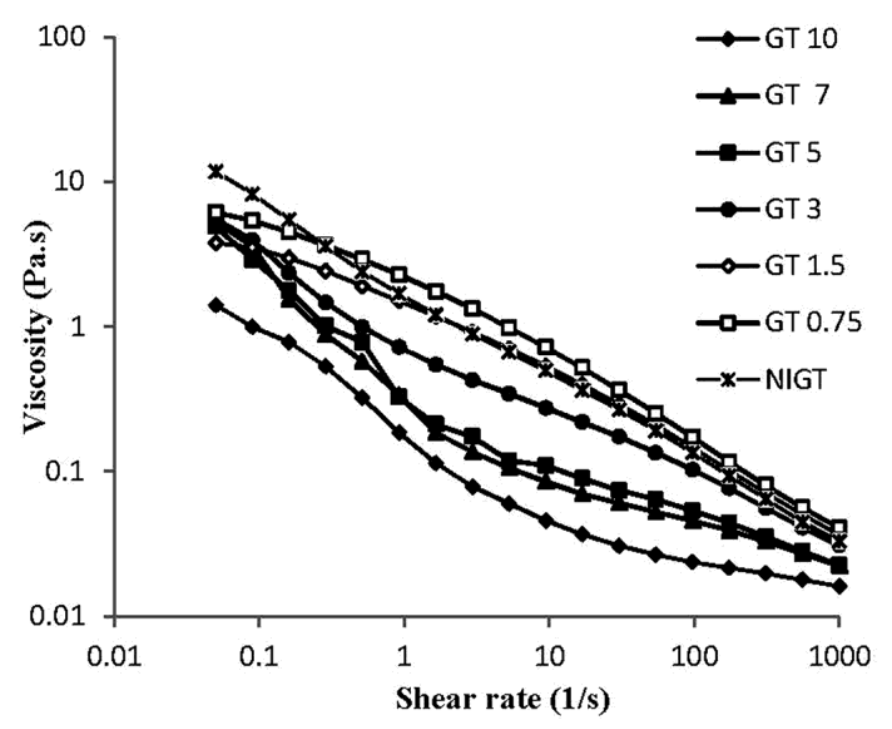


Figure 5.
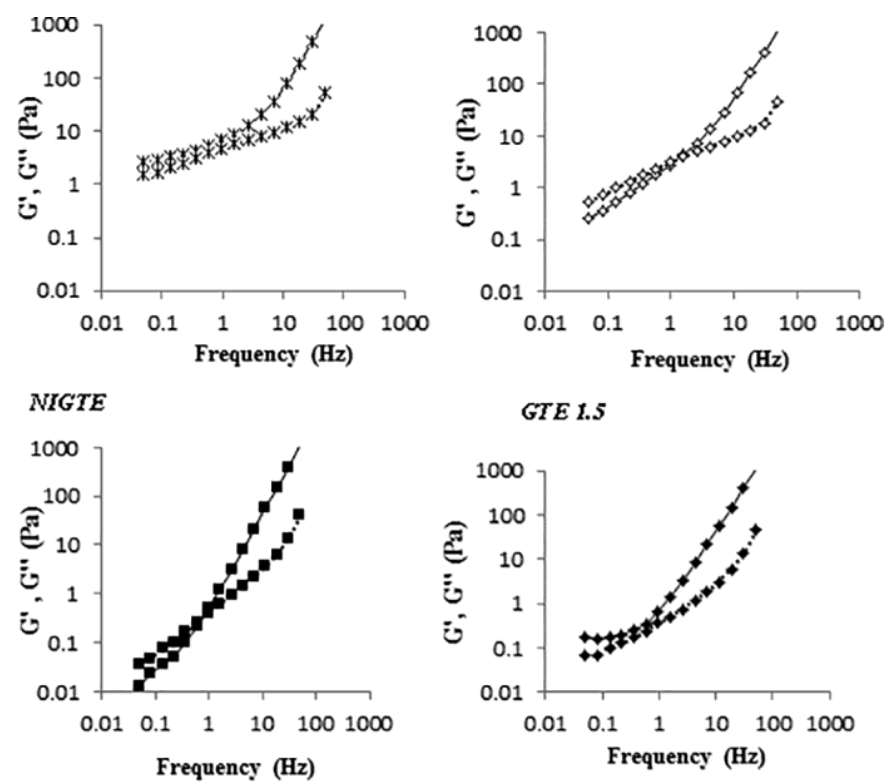

GTE 5

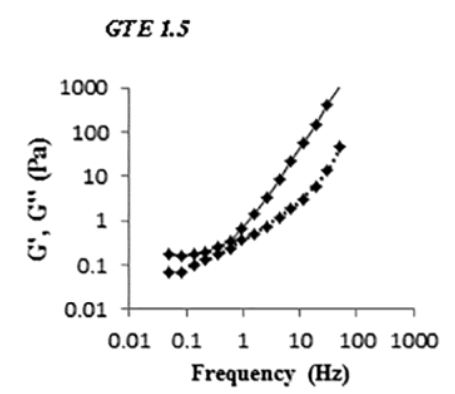

GTE 10 